\title{
EDUCAÇÃO PROFISSIONAL E CURRÍCULO INTEGRADO PARA O ENSINO MÉDIO: ELEMENTOS NECESSÁRIOS AO PROTAGONISMO JUVENIL
}

\author{
M. A. AZEVEDO*, C. D. SILVA e D. L. M. MEDEIROS \\ Instituto Federal de Educação, Ciência e Tecnologia do Rio Grande de Norte \\ lavaniery@gmail.com*
}

Artigo submetido em julho/2015 e aceito em julho/2015

DOI: $10.15628 /$ holos.2015.3190

\section{RESUMO}

Este trabalho compreende uma pesquisa que está sendo desenvolvida junto ao Programa de Mestrado Acadêmico do Programa de Pós-Graduação em Educação Profissional do Instituto Federal de Educação, Ciência e Tecnologia do Rio Grande do Norte - IFRN - Campus Natal-central que tem como objeto o Currículo Integrado e a Educação Profissional. Propomo-nos então, a realizar um estudo bibliográfico sobre Educação Profissional na perspectiva do currículo integrado, como espaço privilegiado do exercício da cidadania, e no desenvolvimento do protagonismo juvenil, um traço importante como estratégia educativa. Analisaremos o referencial bibliográfico que norteia o pensamento clássico e atual sobre os seguintes objetos de estudo: Educação Profissional, Currículo Integrado, eixos estruturantes para o Ensino Médio (Trabalho, Ciência, Tecnologia e Cultura). A pesquisa compreende numa abordagem qualitativa, pesquisa tipo bibliográfica e método descritivo. Adotaremos como procedimento metodológico: 1) estudo bibliográfico; 2) Análise documental; 3) análise de conteúdo do aporte documental estudado; 4) pesquisa on-line. O estudo aponta para a importância da educação profissional baseada na concepção de formação humana omnilateral emancipadora e do trabalho como princípio educativo. 0 ensino médio ancorado nesses sentidos possibilita a formação cidadã para a juventude capaz de compreender a realidade social, econômica, política, cultural, visando contribuir para o alcance dos interesses sociais $e$ coletivos.

PALAVRAS-CHAVE: Eixos estruturantes do Ensino Médio, Educação Profissional, Currículo Integrado Políticas Educacionais.

\section{PROFESSIONAL EDUCATION AND INTEGRATED CURRICULUM FOR SECONDARY EDUCATION: ELEMENTS NECESSARY TO YOUTH LEADERSHIP}

\begin{abstract}
This work includes a survey that is being developed by the Academic Master's Program of the Post-Graduate Professional Education of the Federal Institute of Education, Science and Technology of Rio Grande do Norte - IFRN - Christmas-Central Campus that has as its object the Integrated Curriculum and Vocational Education. We propose then to perform a bibliographic study for vocational education in the integrated curriculum perspective, as a privileged space of citizenship, and the development of youth leadership, an important feature as an educational strategy. We will analyze the bibliographic reference that guides the classic and current thinking on the following objects of study: Professional Education, Integrated Curriculum, structural
\end{abstract}

axes for Secondary Education (Work, Science, Technology and Culture). The study comprises a qualitative approach, research literature and descriptive method. We will take for methodological procedure: 1) bibliographic study; 2) Document analysis; 3) documentary contribution of content analysis study; 4) search online. The study points to the importance of vocational education based on the concept of human development omnilateral emancipatory and work as an educational principle. The high school anchored in these senses enables civic education for young people able to understand the social, economic, political, cultural, to contribute to the achievement of social and collective interests.

KEYWORDS: Structural axes of high school, Vocational Education, Integrated Curriculum Education Policy. 


\section{INTRODUÇÃO}

Na segunda metade da década de 1990 aconteceram grandes debates do que diz respeito à reestruturação da educação e a especificidade da Educação Profissional. No governo de Fernando Henrique Cardoso, em 1996, iniciou-se a concepção das reformulações do antigo ensino técnico profissionalizante, com a primeira versão do que se convencionou chamar de Reforma do Ensino Técnico, corporificada no Projeto de Lei 1.603 (PL 1.603/96) que trazia em seu conteúdo, implicitamente, a extinção do ensino técnico de nível médio.

Mesmo com protestos e repúdio das instituições de educação profissional ligadas à rede federal, e de sua retirada da pauta de votação do Congresso Nacional, tal projeto resultou na criação da Lei de Diretrizes e Bases da Educação Nacional (LDBEN), lei 9.394 de 23 de dezembro de 1996. A perspectiva dos setores populares era a de configurar, na referida lei, um Sistema de Educação que garantisse a universalização e padrão de qualidade educacional, entretanto, os setores conservadores, que representavam o poder hegemônico, retiraram essa proposta, que apresenta uma concepção profissionalizante do ensino médio, do texto da LDB aprovada em 1996, que visa ainda à "preparação para o trabalho", porém não adota a forma compulsória de profissionalização da Lei de Diretrizes e Bases para o ensino de 1ㅇe 20 graus (LDB), Lei 5.692/71, que até então regia a educação profissional de nível médio.

Com efeito, o texto da nova LDB - Lei 9.394/96 - teve como intenção implantar diversos sistemas de ensino que se concretizaram através das legislações específicas de regulamentação. No que se refere à Educação Profissional, a legislação retomou a dualidade estrutural entre educação geral e formação profissional, instituindo um Sistema Nacional de Educação Profissional, que propunha o oferecimento dessa modalidade, em nível técnico, apenas em "articulação" com o ensino médio.

Pode-se destacar, da análise do corpo da LDB - Lei № 9.394/96, que ela traz como concepção da relação trabalho e educação a formação integral do indivíduo para o exercício da cidadania, tendo por pretensão atender às solicitações dos diversos setores da sociedade civil organizada (MULLER \& SUREL, 2002).

No entanto, as políticas para o ensino médio presentes na legislação, mesmo prevendo a formação integral do indivíduo, não asseguravam seu desenvolvimento pela prática cotidiana, permitindo o acesso de poucos ao ensino superior e não respondendo às necessidades de preparo para inserção na atividade profissional.

Segundo Frigotto e Ciavatta (2003) no governo de FHC, período em que se implantaram alterações educacionais brasileiras, do ponto de vista econômico e social, foi um momento de retrocesso no campo teórico, pedagógico e da cidadania, pelo fato do governo ter dado ênfase, baseado na doutrina neoliberal, em tornar o Brasil seguro para o capital. Em tal panorama passamos, segundo os autores, da lei do arbítrio da ditadura civil militar para a ditadura da ideologia do mercado.

Por meio do Decreto $n^{\circ}$ 2.208/1997, do governo de FHC, a Educação Profissional separouse no tempo e no espaço da educação básica de nível médio, como podemos verificar em seu art. 5o: “A educação profissional de nível técnico terá organização curricular própria e independente 
do ensino médio, podendo ser oferecida de forma concomitante ou seqüencial a este" (BRASIL, 1997).

Durante toda a vigência do Decreto $n^{\circ} 2.208 / 1997$, alguns autores, como Kuenzer (2004), Frigotto (2013), Ramos e Ciavatta (2005), estimavam contemplar, no mínimo, as deliberações da LDB 9.394/96, que considera a Educação Profissional prioritariamente integrada ao trabalho, à ciência e à tecnologia, conduzindo o educando ao permanente desenvolvimento de aptidões para a vida produtiva ${ }^{1}$.

Em relação às Diretrizes Curriculares Nacionais para o Ensino Médio, o Conselho Nacional de Educação pronunciou-se sobre o assunto primeiramente pelo Parecer CNE/CEB, CEB n 3, de 26 de junho de 1998, que destaca que as ações administrativas e pedagógicas dos sistemas de ensino e das escolas devem ser coerentes com princípios estéticos, políticos e éticos, abrangendo a estética da sensibilidade, a política da igualdade e a ética da identidade. Afirmam que as propostas pedagógicas devem ser orientadas por competências básicas, os conteúdos e suas formas de tratamento, previstos pelas finalidades do Ensino Médio, e que as competências e habilidades sejam abordadas para a formação dos sujeitos imediatamente voltada para o mercado de trabalho. Ainda, os princípios pedagógicos da identidade, diversidade e autonomia, da interdisciplinaridade e da contextualização são adotados como estruturadores dos currículos. Lembramos que a redação do artigo $39^{\circ}$ da LDB foi alterada pela Lei 11.741 em 2008 da seguinte forma: a educação profissional e tecnológica, no cumprimento dos objetivos da educação nacional, integra-se aos diferentes níveis e modalidades de educação e às dimensões do trabalho, da ciência e da tecnologia.

Desse modo,

Art. 10. As Diretrizes Curriculares Nacionais do Ensino Médio - DCNEM estabelecidas nesta Resolução se constituem num conjunto de definições doutrinárias sobre princípios, fundamentos e procedimentos a serem observados na organização pedagógica e curricular de cada unidade escolar integrante dos diversos sistemas de ensino, em atendimento ao que manda a lei, tendo em vista vincular a educação com o mundo do trabalho e a prática social, consolidando a preparação para o exercício da cidadania e propiciando preparação básica para o trabalho (BRASIL, DCNEM, 1998).

Segundo Santos (2004), de forma geral, a preocupação da resolução será no sentido de manter uma diretriz que responda a tais exigências. Por isso, dos quinzes artigos que compõem a DCNEM, dez tratam de valores éticos e morais necessários à convivência (formação do cidadão e do trabalhador) e de objetivos, concepções e princípios pedagógicos coerentes com essa perspectiva. Os outros cinco trazem propostas de mudanças efetivas para as escolas de Ensino Médio se adequar àquela visão de realidade.

Em 1999, através da resolução CNE/CEB № 04/99, Instituem-se as Diretrizes Curriculares Nacionais para a Educação Profissional de Nível Técnico em conformidade com os artigos 39 a 42 e no § 20 do artigo 36 da Lei Federal no 9.394, de 20 de dezembro de 1996 (LDB), no Decreto Federal no 2.208, de 17 de abril de 1997, e com fundamento no Parecer CNE/CEB 16/99. Desse modo, 
Art. 1ㅇ A presente Resolução institui as Diretrizes Curriculares Nacionais para a Educação Profissional de Nível Técnico.

Estas diretrizes dizem respeito somente ao nível técnico da educação profissional, uma vez que o Decreto no 2.208/97 não dispõe de diretrizes para o nível básico, que é uma modalidade de educação não formal e não está sujeito à regulamentação curricular, mas visa a conduzir ao contínuo aprimoramento do processo da formação de técnicos de nível médio, assegurando sempre a construção de currículos que, atendendo a princípios norteadores, propiciem a inserção e a reinserção profissional desses técnicos no mercado de trabalho atual e futuro.

As tentativas de concretizar esse compromisso, tanto com os trabalhadores quanto com jovens ingressantes no ensino médio, foram firmadas com a revogação do Decreto $n^{\circ} 2.208 / 1997$ pelo Decreto $n^{\circ} 5.154$ em 2004, que, entre outras questões, integrou a educação profissional à educação geral no ensino médio.

A aprovação deste decreto estabelece uma condição diversa à Educação Profissional. Desse modo,

Art. 1으 A educação profissional, prevista no art. 39 da Lei n. 9.394, de 1996, (Lei de Diretrizes e Bases da Educação Nacional), observadas as diretrizes curriculares nacionais definidas pelo Conselho Nacional de Educação, será desenvolvida por meio de cursos e programas de:

I - formação inicial e continuada de trabalhadores;

II - educação profissional técnica de nível médio; e

III - educação profissional tecnológica de graduação e de pós-graduação.

Ao contrário de seu antecessor, esse decreto prevê alternativas de articulação entre o ensino médio e o ensino técnico de nível médio e proporciona a educação integrada, ou seja, ensino médio e ensino profissionalizante. Desse modo, no texto da lei temos:

Art. 4ำ A educação profissional técnica de nível médio, nos termos dispostos no $\S$ 20 do art. 36, art. 40 e parágrafo único do art. 41 da Lei n. 9.394, de 1996, será desenvolvida de forma articulada com o ensino médio, observados:

I - os objetivos contidos nas diretrizes curriculares nacionais definidas pelo

Conselho Nacional de Educação;

II - as normas complementares dos respectivos sistemas de ensino; e

III - as exigências de cada instituição de ensino, nos termos de seu projeto pedagógico.

$\S 10$ A articulação entre a educação profissional técnica de nível médio e o ensino médio dar-se-á de forma:

I - integrada, oferecida somente a quem já tenha concluído o ensino fundamental, sendo o curso planejado de modo a conduzir o aluno à habilitação profissional técnica de nível médio, na mesma instituição de ensino, contando com matrícula única para cada aluno [...]

Posteriormente, pelo Parecer CNE/CEB no 02/2012 que estabeleceu Diretrizes Curriculares Nacionais para o Ensino Médio e orientou os sistemas de ensino e as escolas sobre a questão curricular a todas as formas e modalidades de ensino médio. Desse modo, 
Art. 10 A presente Resolução define as Diretrizes Curriculares Nacionais para o Ensino Médio, a serem observadas na organização curricular pelos sistemas de ensino e suas unidades escolares.

Parágrafo único Estas Diretrizes aplicam-se a todas as formas e modalidades de Ensino Médio, complementadas, quando necessário, por Diretrizes próprias.

Art. 2 As Diretrizes Curriculares Nacionais para o Ensino Médio articulam-se com as Diretrizes Curriculares Nacionais Gerais para a Educação Básica e reúnem princípios, fundamentos e procedimentos definidos pelo Conselho Nacional de Educação, para orientar as políticas públicas educacionais da União, dos Estados, do Distrito Federal e dos Municípios na elaboração, planejamento, implementação e avaliação das propostas curriculares das unidades escolares públicas e particulares que oferecem o Ensino Médio.

As DCNEM concebem a juventude como condição sócio-histórico-cultural de uma categoria de sujeitos que necessita ser considerada em suas múltiplas dimensões, com especificidades próprias que não estão restritas às dimensões biológicas e etárias, mas que se encontram articuladas com uma multiplicidade de atravessamentos sociais e culturais, produzindo múltiplas culturas juvenis ou muitas juventudes. Entender o jovem do Ensino Médio dessa forma significa superar uma noção homogeneizante e naturalizada desse estudante, passando a percebê-lo como sujeito com valores, comportamentos, visões de mundo, interesses e necessidades singulares (PARECER CNE/CEB №: 5/2011).

Trazendo conotações do sujeito para uma formação omnilateral, como ser central no trabalho da escola, então quem são os sujeitos do ensino médio? Estes sujeitos têm a livre escolha de continuar estudando para ter prosseguimento dos estudos ou inserirem-se no mercado de trabalho de forma autônoma.

Como etapa final da educação básica e sua formação, o Ensino Médio precisa estar voltado para o desenvolvimento da pessoa humana, incluindo a ética, o desenvolvimento da autonomia intelectual e o pensamento crítico, que o ser possa compreender os fundamentos científicotecnológicos dos processos produtivos, relacionando a teoria com a prática que precisa estar pautada na preparação básica para o trabalho e a cidadania do educando para continuar aprendendo, de modo a ser capaz de se adaptar às novas condições que lhe são impostas, diferente da anterior que objetiva garantir ao cidadão o direito ao permanente desenvolvimento de aptidões para a vida produtiva e social. (CNE/CEB № 02/2012)

Na definição das Diretrizes Curriculares Nacionais para o Ensino médio há que se enfatizar o que dispõe a LDB em seus artigos 22, 23, 24, 25, 26, 26-A, 27, 35, 36,36-A, 36-B e 36-C 39 a 42, quando dispõe sobre a educação básica e refere-se ao "ensino médio que atendida à formação geral do educando, poderá prepará-lo para o exercício de profissões técnicas e a preparação geral para o trabalho e, facultativamente, a habilitação profissional poderá ser desenvolvida nos próprios estabelecimentos de ensino médio ou em cooperação com instituições especializadas em educação profissional". "a educação profissional integrada às diferentes formas de educação, ao trabalho, à ciência e à tecnologia", conduzindo "ao permanente desenvolvimento de aptidões para a vida produtiva", a ser "desenvolvida em articulação com o ensino regular ou por diferentes estratégias de educação continuada", na perspectiva do exercício pleno da cidadania. (PARECER CNE/CEB №: 5/2011). 
Frigotto, Ciavatta e Ramos (2005) destacam que a integração exige uma relação entre conhecimentos gerais e específicos que seja construída continuamente ao longo da formação, sob os eixos do trabalho, da ciência e da cultura.

\section{DISCUTINDO CURRÍCULO INTEGRADO}

Para que possamos discutir o currículo integrado, buscamos o conceito de currículo em Sacristán, (1995), em que é entendido como a cultura real que surge de uma série de processos, mais que como um objeto delimitado e estático que se pode planejar e depois implantar; aquilo que é na realidade.

Já em GOODSON (1995) o currículo baseado na etimologia, é derivado do verbo latino currère (curso de uma corrida). Esta etimologia apresenta implicações no sentido, que se refere a correr ou lugar onde se corre ido dado atualmente à definição mais tradicional de currículo, relacionado com um curso a ser seguido, ou com a sequência de conteúdos apresentados para estudo. Porém, tal definição encontra objeções, visto que prevê que todos os alunos, que participam da corrida, largam com as mesmas condições e características, o que não possibilita vislumbrar as diferenças existentes entre os alunos e os percursos que estes percorrem no seu trajeto educacional. (PARASKEVA, 2005).

Entendendo o currículo, tal como propõe Carvalho (2004), como "um dispositivo pedagógico engendrado em contextos diversos que, por sua vez se dão em uma intertextualidade de versões estéticas, políticas e discursivas", percebemos que ele é um dispositivo pedagógico potencial para ampliar os horizontes cognitivos do estudante sem deixar de considerar as realidades sociais e culturais nas quais ele se insere.

O currículo corporifica os nexos entre o saber, poder e identidade, diz Silva (1999). Ele é um meio não somente para se apresentar conteúdos, sugerir expectativas de aprendizagem, mas também orientar a escolha de materiais didáticos, planos e práticas de aula do docente, rumos dos projetos de ensino e pesquisa da escola, e, sobretudo, o exercício de uma política de humanização que considere o sujeito com o qual se trabalha, a quem educamos.

O discurso sobre Currículo Integrado, no Brasil, é reacendido na década de 1990 quando da discussão e mobilização por uma educação pública de qualidade em nosso país e no bojo das reformas educacionais deste período. Entretanto, essa discussão foi adiada quando da instituição do Decreto n. 2.208/97 que separa de forma estrutural o Ensino Médio da Educação Profissional. Em 2003 e 2004 o debate focaliza a revogação do Decreto n. 2.208/1997 e a elaboração do Decreto n. 5.154/2004 com uma possibilidade de integração do Ensino Médio com a Educação Profissional. A integração:

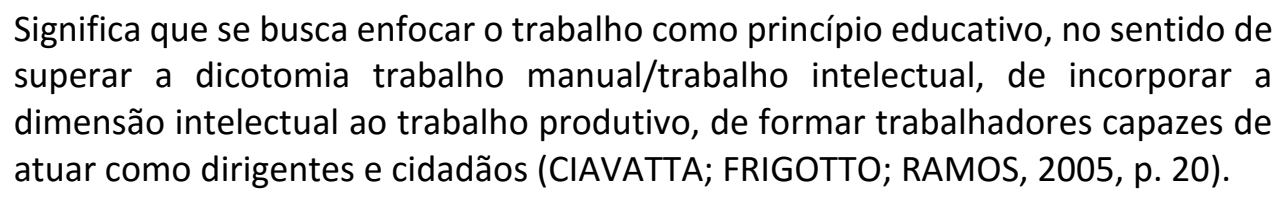

Essa perspectiva de currículo integrado percebe a realidade como um todo concreto. Para Ciavatta o currículo integrado está relacionado na totalidade da formação do ser humano: 
Como formação humana, o que se busca é garantir ao adolescente, ao jovem e ao adulto trabalhador o direito a uma formação completa para a leitura do mundo e para a atuação como cidadão pertencente a um país, integrado dignamente à sua sociedade política. Formação que, neste sentido, supõe a compreensão das relações sociais subjacentes a todos os fenômenos (CIAVATTA; FRIGOTTO; RAMOS, 2005, p. 85).

O Currículo Integrado é uma tentativa de possibilitar aos estudantes o acesso aos conhecimentos científicos e culturais da humanidade, para que possam ter acesso a espaços para o desenvolvimento da experimentação e das práticas de estudo e investigação. Neste contexto, precisa de uma atitude docente diferenciada que passa necessariamente pelo processo de formação inicial e continuada que deve estar subjacente à Política Pública de Educação Profissional. Daí se afirmar que um ensino que pretende formar um profissional crítico, que seja capaz de refletir sobre sua condição social e participar das lutas em favor dos interesses da coletividade, característica plena do que resulta um Currículo Integrado, seja o seu diferencial em relação aos projetos vinculados aos interesses de mercado.

\section{DESENVOLVIMENTO DO PROTAGONISMO JUVENIL}

A estratégia propiciadora do desenvolvimento de adolescentes, assim como do desenvolvimento de qualidades que o capacitam para ingressar, permanecer e ascender no mundo do trabalho precisa ter uma participação consciente em atividades, projetos de caráter público, que podem ocorrer no espaço escolar ou na comunidade: campanhas, movimentos, trabalho voluntário ou outras formas de mobilização (GOMES, 2001).

Traço importante como estratégia educativa na perspectiva aqui apresentada, coaduna com o conceito do Protagonismo Juvenil. Neste trabalho concebemos protagonismo juvenil a partir de Gomes (2011, p. 15). O termo "protagonismo" refere-se à nossa capacidade de participar e influir no curso dos acontecimentos, exercendo um papel decisivo e transformador no cenário da vida social. Exercer o protagonismo significa não ser indiferente em relação aos problemas de nosso tempo.

No campo do desenvolvimento pessoal (aprender a ser), a prática do protagonismo contribui para o desenvolvimento do senso de identidade, da autoestima, do autoconceito, da confiança, da visão do futuro, do nível de aspiração vital, do projeto e do sentido da vida, da autodeterminação, da autorrealização e da busca pela plenitude humana por parte dos jovens.

Já no campo da capacitação para o trabalho (aprender a fazer), o protagonismo propicia ao jovem, através de práticas e vivências estruturantes, o desenvolvimento de habilidades como autogestão, heterogestão e cogestão, ou seja, ele aprende a lidar melhor com suas potencialidades e limitações( gerir a si mesmo), a coordenar o trabalho de outras pessoas( atuar sobre a atuação de outros) e a agir conjuntamente com outros adolescentes e adultos na consecução de objetivos comuns (trabalho em equipe)

Nesse sentido, o protagonismo juvenil diz respeito à atuação criativa, construtiva e solidária do jovem, junto a pessoas do mundo adulto (educadores), na solução de problemas reais na escola, na comunidade e na vida social mais ampla. 
O objetivo é que os jovens possam ir construindo sua autonomia através da prática, da situação real, do corpo a corpo com a realidade, a partir da participação ativa, crítica e democrática em seu entorno social.

\section{A INTEGRAÇÃO DOS EIXOS ESTRURANTES DO ENSINO MÉDIO}

Trabalho, ciência, tecnologia e cultura: eixos estruturantes do ensino médio, precisam estar incorporadas ao currículo contribuindo para uma formação omnilateral dos sujeitos. Partimos do conceito de trabalho, contido no PARECER CNE/CEB №: 5/2011 que se apresenta, na sua perspectiva ontológica de transformação da natureza, como realização inerente ao ser humano e como mediação no processo de produção da sua existência. Esta dimensão é, assim, o ponto de partida para a produção de conhecimentos e de cultura pelos grupos sociais.

O caráter teleológico da intervenção humana sobre o meio material, isto é, a capacidade de ter consciência de suas necessidades e de projetar meios para satisfazê-las, diferencia o ser humano dos outros animais, uma vez que estes não distinguem a sua atividade vital de si mesmos, enquanto aquele faz da sua atividade vital um objeto de sua vontade e consciência.

As DCNEM's trazem o trabalho, como princípio educativo, sendo a base para a organização e desenvolvimento curricular em seus objetivos, conteúdos e métodos. Considerar o trabalho como princípio educativo equivale a dizer que o ser humano é produtor de sua realidade e, por isto, dela se apropria e pode transformá-la. Equivale a dizer, ainda, que é sujeito de sua história e de sua realidade.

Segundo Moura (2012) É importante esclarecer que compreendemos o trabalho como princípio educativo, considerando, portanto, o seu caráter histórico e ontológico na produção da existência humana. Nesse sentido, compreendemos que uma prática pedagógica significativa demanda análises sobre o mundo do trabalho (sem reduzi-lo apenas ao espaço onde ocorre o trabalho assalariado), incluindo, a sua cultura, os conflitos nele existentes e suas vinculações aos projetos societários em disputa, suas relações com e implicações sobre a natureza, os conhecimentos construídos a partir do trabalho e das relações sociais que se estabelecem na sua produção.

Diante das relações geradas no atual contexto social entre educação e trabalho, em que demandas produtivas advindas de novas tecnologias, novos modelos de gestão e produção reservam conhecimentos científicos e tecnológicos a grupos específicos, é importante discutir que tipo de Educação Profissional está sendo ofertada e qual é a forma mais coerente e vantajosa de Educação Profissional para os trabalhadores (CIAVATTA; TREIN 2006).

Desta forma, a sociedade também é compreendida pelo relacionamento ciênciatecnologia, sendo que a distinção entre ambas não se apresenta, segundo os autores Pinch e Bijker (1997) entre as funções abstratas do saber e do fazer. A ciência, portanto, que pode ser conceituada como conjunto de conhecimentos sistematizados, produzidos socialmente ao longo da história, na busca da compreensão e transformação da natureza e da sociedade, se expressa na forma de conceitos representativos das relações de forças determinadas e apreendidas da realidade. Aparece como um tratamento teórico dos problemas e a tecnologia como a prática, a aplicação desta teoria. Nessa linha de pensamento, o entendimento inicial de que poderia vir a compor uma dicotomia, representada pela distância entre saber e fazer se resolve, em princípio, 
quando consideramos que ciência e tecnologia têm um elo universal: o fato de que são sociais e históricas. A ciência e a tecnologia podem ser definidas como um conjunto complexo que compreende e associa dispositivos técnicos, saberes e saber-fazer. Elas são compreendidas também como uma representação dos métodos disponíveis ou pertinentes para resolver algumas necessidades, ou ainda um conjunto de ideias sobre as experiências, que podem dar visibilidade sobre o futuro possível ou provável para as tecnologias (PINCH e BIJKER, 1997).

O desenvolvimento da tecnologia visa à satisfação de necessidades que a humanidade se coloca, o que nos leva a perceber que a tecnologia é uma extensão das capacidades humanas. A partir do nascimento da ciência moderna, pode-se definir a tecnologia, então, como mediação entre conhecimento científico (apreensão e desvelamento do real) e produção (intervenção no real).

Tecnologia, ciência e educação são espaços atualmente interdependentes e merecem ampla discussão. Pucci (2005) problematiza esta relação ao dizer que a tecnologia influencia nossas formas de viver, pensar e agir social e individualmente, e o paradigma tecnológico atual são derivados das inovações tecnológicas ocorridas pelas "fusões" entre diferentes tipos de tecnologia, mais do que por "rupturas tecnológicas". E ainda, "O princípio de competitividade obriga 'a racionalidade econômica a atrelar-se à racionalidade tecnocientífica' e subordinar as decisões de investimentos à dinâmica de inovação".

Entendemos cultura como o processo de produção de símbolos, de representações, de significados e, ao mesmo tempo, prática constituinte e constituída do/pelo tecido social, norma de comportamento dos indivíduos numa sociedade e expressão da organização política dessa sociedade, no que se refere às ideologias que cimentam o bloco social (GRAMSCI, 1991).

Por essa perspectiva, a cultura deve ser compreendida no seu sentido mais ampliado possível, ou seja, como a articulação entre o conjunto de representações e comportamentos e o processo dinâmico de socialização, constituindo o modo de vida de uma população determinada. Uma formação integral, portanto, não somente possibilita o acesso a conhecimentos científicos, mas também promove a reflexão crítica sobre os padrões culturais que se constituem em normas de conduta de um grupo social, assim como a apropriação de referências e tendências que se manifestam em tempos e espaços históricos, os quais expressam concepções, problemas, crises e potenciais de uma sociedade, que se vê traduzida e/ou questionada nas suas manifestações.

Já a cultura é afirmativa, neste sentido, porque ao pretender conciliar o particular e o universal - e de início é bem sucedida - assegurou de forma generalizada a cultura burguesa. É no plano das ideias que a burguesia arquiteta seu mote de liberdade e igualdade: os indivíduos se tornam iguais na medida em que a cultura universaliza o espírito e, são livres enquanto são condicionados pelas relações de troca.

A cultura se define ao mesmo tempo como produção material e imaterial da vida. Esta discussão é atual, pois, ao nos depararmos com os insistentes antagonismos entre teoria e prática, trabalho e lazer, e classes sociais, percebemos por fim a Indústria Cultural, que atualmente tudo suplanta e deforma. Em síntese, o conceito de cultura,

(...) rejeitou a noção sociológica dominante, segundo a qual a cultura existe de modo autônomo, não relacionada com os processos da vida econômica e política da sociedade. Argumentavam que tal perspectiva neutralizava a cultura e, desse 
modo, abstraía-a do contexto histórico e social que lhe dava significado (GIROUX, 1983, p. 20).

Por essa razão, trabalho, ciência, tecnologia e cultura são instituídos como base da proposta e do desenvolvimento curricular no Ensino Médio de modo a inserir no contexto escolar o diálogo permanente com as diferentes áreas do conhecimento.

\section{CONSIDERAÇÕES FINAIS}

O ensino médio no Brasil desenvolve-se como mero nível de ensino, em detrimento da busca ampliada de suas finalidades. Nesta fase não tem sido assegurado ao jovem brasileiro, pertencente à escola pública, a consolidação e o aprofundamento do ensino fundamental, bem como outros tantos desafios necessários a etapa final da educação básica.

Assim, o Brasil para exercer um protagonismo de desenvolvimento escolar no mundo precisa ultrapassar desafios da educação básica para toda a sua população. Conforme pontuamos, as Diretrizes Curriculares Nacionais do Ensino Médio celebram a importante concepção de formação humana omnilateral e emancipatória, bem como o trabalho como princípio educativo, se constituindo como um importante instrumento norteador para as práxis do ensino médio.

A escola com a formação voltada para os jovens, não deve ser apenas espaço de procedimentos voltados para a operacionalização do currículo conceitual. É preciso uma formação capaz de formar cidadãos para a compreensão crítica da realidade social, econômica, política, cultural, que contribua para a transformação da sociedade em função dos interesses sociais e coletivos. Porém, a revisão bibliográfica reconhece também que a importante concepção das Diretrizes Curriculares Nacionais do Ensino Médio isoladamente não pode transformar-se em política pública se não for acompanhada de outras dimensões, como financiamento, constituição qualitativa e quantitativa do quadro de profissionais da educação, adequada formação inicial e continuada desses profissionais, cenário institucional escolar, dentre outras.

\section{REFERÊNCIAS BIBLIOGRÁFICAS}

1. BRASIL/CNE/CEB. Resolução CNE/CEB № 04/99, Institui as Diretrizes Curriculares Nacionais para a Educação Profissional de Nível Técnico. http://portal.mec.gov.br/setec/arquivos/ pdf/RCNE_CEB04_99.pdf Acessado em 15 de setembro de 2013.

2. BRASIL. Leis, Decretos. Lei n. 5.692, 11 de agosto de 1971. Documenta, Rio de Janeiro, n. 129, p. 400-416, ago. 1971. Fixa as diretrizes e bases para o ensino de 1ㅇ e 2 graus.

3. BRASIL. Projeto de Lei 1.603/96. Dispõe sobre a Educação Profissional e organização da Rede Federal de Educação Profissional.

4. BRASIL/CNE/CEB. Resolução CEB no 03 de 26/06/98. Institui as DCN para o Ensino Médio.

5. BRASIL. Lei Federal $n^{\circ}$ 9.394/96, de 20 de dezembro de 1996. Lei das Diretrizes e Bases da Educação Nacional (LDBEN). Estabelece as Diretrizes e Bases da Educação Nacional. Educação Profissional: legislação básica. 5.ed. Brasília: MEC, 2001.

6.

Decreto no 2.208/97 de 17 de abril de 1997. Regulamenta o parágrafo 20 do art. 36

e os artigos 39 a 42 da Lei no 9394, de 20 de dezembro de 1996, que estabelece as diretrizes 
e bases da educação nacional. Diário Oficial da União, Brasília, DF, 18 de abr. 1997.

7.

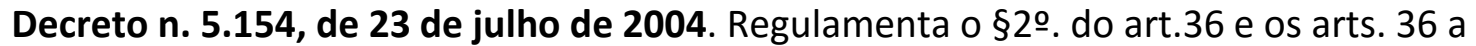
42 da lei 9.394, de 20 de dezembro de 1996, que estabelece as diretrizes e bases da educação nacional e dá outras providências.

$8 . \quad$ Lei n. 11.741 , de 16 de julho de 2008. Altera dispositivos da Lei n. 9.394, de 20 de dezembro de 1996. Disponível em: <http://www.legislação.planalto.gov.br>. Acesso em: 26 setembro 2013

9. CARVALHO, Rosângela Tenório. Discursos pela interculturalidade no campo Curricular da Educação de Jovens e Adultos no Brasil nos anos 1990. Recife: UPEP/UFPE:Edições Bagaço, 2004.

10. CIAVATTA, M.; TREIN, E. A Transformação do Trabalho e a Formação Profissional na Sociedade da Incerteza. In: 29ạ Reunião Anual da Associação Nacional de Pesquisa e PósGraduação em Educação - Anped. Caxambu, MG, 2006.

11. COSTA, A. C. G da; VIEIRA, M. A. Protagonismo Juvenil: adolescência, educação e participação democrática. São Paulo: FTD, 2006.

12. FRIGOTTO, Gaudêncio; CIAVATA, Maria. Educação Básica no Brasil na Década de 1990: subordinação ativa e consentida à lógica do mercado. Educação \& Sociedade, Campinas, vol.24, n.82, p.93-130, abril 2003. Disponível em http://www.cedes.unicamp.br Avaliado em 09 de março de 2013

13. FRIGOTTO, G. CIAVATTA, M. RAMOS, M. (org). Ensino Médio Integrado: concepções e contradições. São Paulo: Cortez, 2005.

14. GIROUX, H.Pedagogia Radical: subsídios. São Paulo: Cortez: Autores Associados, 1983.

15. GRAMSCI, A. Os intelectuais e a organização da cultura. 8. ed. Rio de Janeiro: Civilização Brasileira, 1991.

16. GUIMARÃES, E. R. POLÍTICA PARA O ENSINO MÉDIO E EDUCAÇÃO PROFISSIONAL GT - 05: Estado e Política Educacional. 2001. Disponível www.anped.org.br/reunioes/28/textos/ gt05/GT05-1331--Int.rtf 10 de outubro de 2013

17. GOODSON,Ivor F. currículo:teoria e história.7ạ Ed.Petropolis,RJ:Vozes,2005.

18. GOMES DA COSTA, Antonio Carlos. Tempo de servir: o protagonismo juvenil passo a passo; um guia para o educador. Belo Horizonte: Editora Universidade, 2001.

19. GIMENO SACRISTÁN J.: Aproximação ao conceito de currículo. O currículo: uma reflexão sobre a prática. Porto Alegre: ArtMed, 1998. Cap. 1, p. 13-87.

20. Ministério da Educação. Conselho Nacional de Educação. PARECER CNE/CEB №: 5/2011. Define Diretrizes Curriculares Nacionais para o Ensino Médio. Brasília, DF: 04 de maio de 2011.

21. Ministério da Educação. Conselho Nacional de Educação. RESOLUÇÃO № 2, DE 30 DE JANEIRO 2012. Define Diretrizes Curriculares Nacionais para o Ensino Médio. Brasília, DF: 30 de janeiro de 2012.

22. Ministério da Educação. Conselho Nacional de Educação. Resolução CNE/CEB № 04/99, Institui as Diretrizes Curriculares Nacionais para a Educação Profissional de Nível Técnico. Brasília, DF: abril 1999. 
23. MULLER, Pierre \& SUREL, Yves. A Análise das Políticas Públicas. Tradução: Agemir Bavaresco, Alceu R. Ferraro. Pelotas: Educat, 2002.

24. PARASKEVA, João M. Currículo: necessidade ou não de uma definição. Seminário Teoria Curricular. Pelotas: FaE-UFPEL, 2005.

25. PINCH, T. F.; BIJKER, W. E. The social construction of facts e artifacts: or how the Sociology of Science and the Sociology of Technology might benefit each other. In: PUCCI, B. (org). Teoria crítica e educação: a questão da formação cultural na Escola de Frankfurt. Petrópolis, RJ: Vozes; São Carlos, SP: EDUFISCAR, 1997. 2a Edição

26. SACRISTAN, J. Gimeno. Poderes instáveis em educação. Tradução de Beatriz Affonso Neves. Porto Alegre: Artmed, 1999

27. SANTOS, E. H. Metodologia para a construção de uma política de formação inicial e continuada de profissionais da educação profissional e tecnológica. Brasília: MEC, 2004.

28. SILVA, Tomaz Tadeu da. O currículo como fetiche: a poética e a política do texto curricular. Belo Horizonte: autêntica, 1999. 